\title{
The BMP Consensus Challenge
}

\author{
Thomas H. Yeager ${ }^{1}$
}

ADDITIONAL INDEX WORDs. container plant production, water quality, Broward County

SumMary. The nursery industry in Broward County, Fla., had to choose between partaking in the resolution needed to achieve $10 \mathrm{ppb}$ total phosphorus discharged to the Everglades or face regulation. The industry decided to pursue the proactive route and implement best management practices (BMPs). Teams of industry personnel were formed to develop the content of the Florida Container Nursery BMP Guide that contained the following chapters: 1) nursery layout, 2 ) container substrate and planting practices, 3) fertilization management, 4) container substrate nutrient monitoring, 5) irrigation water quality, 6) irrigation application, 7) irrigation uniformity, 8) erosion control and runoff water management, 9) pesticide management, and 10) waste management. Each team was to determine the content of their chapter, based on cultural practices producers were currently using, or could be using, which would minimize or reduce surface water movement of phosphorus from the nursery to adjacent water. Cultural practices, brought forth after a consensus was achieved by each team in concert with governmental agencies, associations, and allied industries, were meshed with research information, or the "best" information available from academic sources to ensure that the resolutions or BMPs that were written would contribute to resolving the conflict (i.e., elevated total phosphorus in canal waters). Consensus development is a new challenge for most academicians but it is important because unbiased and science-based knowledge is needed to assist in BMP development. Furthermore, consensus of those directly and indirectly involved in the nursery industry helps facilitate the use of BMPs. Once the Florida Container Nursery BMP Guide is adopted by rule under the statutory authority of the Florida Department of Agriculture and Consumer Services, nursery operators voluntarily using the BMPs and keeping appropriate records will receive a waiver of liability from cleanup costs associated with contaminated ground or surface water, and be presumed to be in compliance with state water quality standards.

$\mathrm{T}$ The definition of BMPs may vary according to the scope or subject addressed by the practices. For example, a federal definition refers to protection of the air and waters of the United States; whereas a definition from Florida Department of Agriculture and Consumer Services (FDACS) refers to technically and economically feasible practices for protection or improvement of water quality. In essence, BMPs are implemented because they are effective and economical ways of improving water quality or minimizing the impacts on water quality of natural areas without sacrificing yield.

BMPs are often developed because of conflicts or opposing interpretations of public policy. In the 1990s, elevated groundwater nitrate nitrogen in citrus

\footnotetext{
This project supported by the Florida Agricultural Experiment Station and grants from the National Foliage Foundation and Florida Department of Agriculture and Consumer Services.

${ }^{1}$ University of Florida, IFAS, PO Box 110670 Gaines ville, FL 32611; e-mail: tyeager@ifas.ufl.edu
}

(Citrus spp.) groves in central Florida resulted in the development of nutrient management BMPs, as did elevated nitrate nitrogen in drinking water wells in the fern production area of northeastern Florida. In both instances, the growers claimed to follow university recommendations, but nitrate nitrogen concentrations exceeded those acceptable to regulators; consequently, conflict resulted.

Conflicts may be resolved by tradition, science, and consensus (Moscovici and Doise, 1994). The construction of a fence between the properties of neighbors because of conflicts that have developed exemplifies tradition as a way to solve conflict. Conflicts between neighbors often arise because of pets or people that visit the neighbor's property without permission. The neighbors could discuss their conflicts among themselves, or consult with others in and outside the neighborhood to obtain as many opinions, or as much information as possible before deciding to construct a fence. During the discussions, it may be determined by the neighbors in conflict that other resolutions to the conflicts were not considered. Based on discussions with persons in the neighborhood and others outside the neighborhood, as well as the information they provided, a resolution or outcome may be reached by consensus. The resolution may not be the desired outcome according to those originally involved in the conflicts, but the resolution is agreeable and supported by a larger group (i.e., the neighborhood and others outside the neighborhood) than those affected directly. This agreement assures support for the resolution if challenged. For example, a newcomer to the neighborhood may challenge the necessity for having a fence, but the large base of support for the fence would negate this challenge.

Consensus ensures support for resolution to a conflict; however, science based on research provides a firm foundation upon which resolutions are built. Without a scientific foundation, a resolution is based on the "best" information available. BMPs are an agreed-upon resolution that may or may not have resulted from conflict, but BMPs are usually developed with consensus considering scientific information. It is important to consider scientific information when developing BMPs; however, there may be a total or partial lack of scientific information for a particular issue. Consequently, the "best" information available should prevail. But regardless of the scientific information available, a consensus has to be developed for information that is the foundation of a BMP. When developing this consensus, it is imperative for academic or scientific persons to participate in the consensus building process, particularly when scientific research findings are being discussed. Academic or scientific persons also have a responsibility to contribute scientific information to the consensus building

\begin{tabular}{llll}
\hline $\begin{array}{l}\text { Units } \\
\begin{array}{l}\text { To convert U.S. to SI, } \\
\text { multiply by }\end{array}\end{array}$ & U.S. unit & SI unit & $\begin{array}{l}\text { To convert SI to U.S., } \\
\text { multiply by }\end{array}$ \\
\hline 2.5900 & $\mathrm{mile}^{2}$ & $\mathrm{~km}$ & 0.3861 \\
1 & $\mathrm{ppb}$ & $\mu \mathrm{g} \cdot \mathrm{L}^{-1}$ & 1
\end{tabular}


process when the "best" information is being discussed as the foundation for a BMP. However, regardless of the amount of scientific information brought forth and discussed for achieving a consensus on resolving a conflict, some aspects of the science are often challenged. Thus, it is a "give and take" situation involving scientific interpretations throughout the discussions for arriving at resolutions to the conflict. Participation by nonscientific or nonacademic persons along with scientific or academic persons in the consensus building process results in a feeling of ownership, and likely a greater participation or use of the BMPs when finalized. After the southern Florida nursery industry leaders realized that BMPs were needed to achieve a specific objective, in this case $10 \mathrm{ppb}$ total phosphorus in water discharged to the Everglades, they engaged the process of developing BMPs embraced by consensus of those within and outside the nursery industry. In this paper, I will outline the BMP development process followed by southern Florida container nursery plant producers where consensus and science were meshed for addressing a water quality issue.

\section{A water quality issue}

The Clean Water Act was enacted in 1972 to protect surface waters such as rivers, streams, and wetlands from point source discharge of pollutants. This act has resulted recently in environmental regulatory agencies of each state establishing total maximum daily loads (TMDLs) for nutrients in agricultural runoff that may impact waters of the states. In a few years, the regulatory agencies in each state will have established nutrient loading criteria for natural waters. However, the South Florida Water Management District (SFWMD) is already under a mandate in Broward County to reduce phosphorus concentration in the C-11 canal that discharges to the Everglades. This mandate is outlined in the Everglades Forever Act of 1994 (Florida Statutes, 2000).

SFWMD is responsible for the maintenance of the C-11 canal, and secondary canals that flow to the C-11 canal are maintained by three drainage districts that make up the C-11 West Basin: South Broward Drainage District, Central Broward Water Control District, and Indian Trace Drainage
District. The Drainage Districts encompass about 72 square miles, and land use is approximately $61 \%$ developed and $16 \%$ agriculture (Adorisio et al., 2004), which is primarily container and field-grown nursery plants. Wetlands, forests, and rangelands are also present. Average total phosphorus concentrations at selected locations in the C-11 West Basin canal waters for 2000-03 are given in Table 1.

In early 2003, the SFWMD asked the Florida Nursery, Growers and Landscape Association (FNGLA) members in Broward County to participate in developing and implementing BMPs as a way to improve canal water quality. Subsequently, FDACS became involved in the process at the request of FNGLA because the Office of Agricultural Water Policy (OAWP) of FDACS is responsible for overseeing the development of BMPs that are adopted by rule with statutory authority given to FDACS. The BMPs must be economically and technically feasible and developed with grower input. FDACS relies on input of expertise from university personnel to ensure the BMPs are research-based to the extent possible. Also, regulatory personnel of the state are involved in the BMP development process to ensure that BMPs provide the "backbone" for addressing water quality issues.

\section{BMP development}

In late 2003 , a group of nursery operators from southern Florida, representing FNGLA, met with university personnel and regulatory and nonregulatory personnel to achieve a resolution for the elevated concentration of phosphorus in the canals of the drainage districts that transfer water to the C-11 canal, then to the Everglades. During a series of meetings in Broward County, FDACS and the University of Florida discussed with industry the topics they thought should be the subject of a BMP guide or manual. In early 2004 , nursery industry personnel from southern Florida agreed to lead the development of the following topics or chapters: 1) nursery layout, 2) container substrate and planting practices, 3 ) fertilization management, 4) container substrate nutrient monitoring, 5 ) irrigation water quality, 6) irrigation application, 7) irrigation uniformity, 8 ) erosion control and runoff water management, 9) pesticide management, and 10) waste management.
Table 1. Average total phosphorus concentrations of canal waters at selected locations in the C-11 West Basin of Broward County, Fla., for 2000-03 (Adorisio et al., 2004).

\begin{tabular}{lcc}
\hline $\begin{array}{l}\text { Drainage } \\
\text { district }\end{array}$ & $\begin{array}{c}\text { Total } \\
\text { phosphorus } \\
{\left[\mathrm{ppb}\left(\boldsymbol{\mu g} \cdot \mathrm{L}^{-1}\right)\right]}\end{array}$ & $\begin{array}{c}\text { Sampling } \\
\text { locations } \\
(\text { no. })\end{array}$ \\
\hline Indian Trace & 16 & 6 \\
South Broward & 88 & 20 \\
Central Broward & 33 & 14 \\
\hline
\end{tabular}

The content of each chapter was developed by a team with a leader from the nursery industry. During this process, numerous meetings and discussions with as many nursery plant producers as possible took place. Representatives from governmental agencies, associations, allied industries, and educational institutions were also members of the teams that worked independently, but would periodically discuss the content of their chapter in open forum with other teams and interested persons not associated with a team. Team members included persons from Dade County and Palm Beach County in addition to Broward County, so the BMP document that was written would apply to a broad base of nursery practices. Each team was to determine the content of their chapter, based on cultural practices producers were currently using, or could be using to reduce surface water movement of phosphorus from the nursery to adjacent water. My role was not only to facilitate discussion and record the practices or resolutions each team selected, but also to ensure the cultural practices brought forth after a consensus by each team were meshed with research information and to ultimately decide if the resolution or BMP that was written would likely contribute to resolving the conflict, i.e., elevated total phosphorus in canal waters. This process evolved into a draft document titled Florida Container Nursery BMP Guide (Yeager, 2005). The document has a similar format to Best Management Practices Guide for Producing Container-Grown Plants, printed by the Southern Nursery Association (Yeager et al., 1997), which provided background information for the team leaders and participants who developed the BMP document for southern Florida. A major difference is that the Guide will be used by container plant producers to assess their 
nursery by marking in the Guide those practices they are currently using, those practices they plan to implement, and when they will be implemented. A copy of the assessment is sent to FDACS with a notice of intent (NOI) form that formally commits the nursery to follow the BMPs listed in their assessment. Thus, the nursery personnel have a plan that, once implemented and carried out, along with keeping required records specified in the Guide, qualifies the nursery for a waiver of state-imposed liability for surface and ground water cleanup and presumption of compliance with state water quality standards. The liability waiver and presumption are provided by the state of Florida because the Guide is referenced or adopted by statutory rule during a formal process completed by FDACS. This presumption is administered by FDACS' OAWP. Florida Department of Environmental Protection (FDEP) resolves any contesting of the water quality. FDEP was involved in the process to develop the BMPs, so the content of the BMPs are within the scope of their regulatory authority. Subsequently, if there is a water quality complaint, the nursery is presumed to be in compliance with state water quality standards and waived of cleanup costs imposed by state liability, providing the nursery has records to show they followed the BMPs they committed to use as listed on the NOI filed with FDACS.

BMPs are given in the Guide as specific pieces of identifiable text that are the action portion of a more elaborate discussion. BMPs have a specific objective to achieve a defined result, i.e., resolution. For example, in the chapter on nutrient monitoring, the nutrient ranges given for substrates are based on research, and enable the nutrient applicator to apply fertilizer only when needed. Other examples of BMPs state that substrate storage piles are covered with an impermeable barrier to prevent loss of nutrients during rain events, and irrigation uniformity should be at least $80 \%$ because nonuniform water delivery results in nutrients leaching where excess water is applied.

\section{Assistance with BMP costs and implementation}

Many nursery operations are currently using some of the BMPs in the Guide, but others will need to change or implement new practices if they choose to voluntarily use BMPs. Change is not easy psychologically and can also be costly. To help defray some costs, a cost share program has been established in which $80 \%$ of the costs of construction for a BMP can be paid for by Palm Beach Soil and Water Conservation District (PBSWCD). The cost share program is administered by PBSWCD with funding provided by FDACS and SFWMD. The first year $\$ 400,000$ was available in Broward County for cost share with $\$ 320,000$ proposed for each of the two subsequent years. To assist nurseries with the decisions about which BMPs to implement, a mobile irrigation lab funded by FDACS is conducting site visits. Additionally, the mobile irrigation lab staff can conduct an irrigation uniformity test and suggest improvements that can be cost shared by the nursery.

\section{Education}

Workshops have been conducted by University of Florida personnel in several locations in southern Florida to assist nursery operators with implementation of BMPs. The workshop format enables hands-on experiences with calculation of irrigation uniformity, substrate physical property determination, and measuring container substrate nutritional levels. Workshop participants also conduct an assessment of BMPs used at a nursery. The workshops are conducted with the participation of University of Florida county extension faculty and FDACS personnel.

Nurseries have been selected by University of Florida to serve as BMP demonstration sites based on 1) nutrient data collected previously from canal waters, 2) the physical infrastructure of a nursery, or 3 ) willingness of owner to cooperate. For example, implementation of a grassed water conveyance area or runoff water collection structure would trap or allow suspended sediments in water to flocculate, thus cleaning the water before discharge to the canal. Data will be collected to verify the effectiveness of the grassed waterway and collection structure. Interested persons will be able to view the demonstration and learn about the effectiveness of the BMPs during field days conducted by University of Florida personnel.

\section{The future}

The nursery industry has a tremendous opportunity to engage its future direction and waive liability by embracing the management strategies or practices agreed to be "best" for the industry. Their future will depend on how well agencies, industry, universities, and associations work together to not only confront and solve the water quality issues, but to leap forward using new production technology. Proactive steps now will mean even greater opportunities in the future as environmental stewards. In addition to the waiver of state-imposed liability for contamination of ground and surface water, and the presumption of compliance with state water quality standards, the use of BMPs by container plant producers offers other benefits that include the following:

- Protection from duplicate regulations at the local level;

- Eligibility for USDA Natural Resources Conservation Service and possibly other cost share funds for retrofitting or implementing waterconserving irrigation systems;

- A demonstration that the nursery industry can exercise its ability to determine what are the "best" cultural practices and voluntarily use these practices rather than be confronted with mandatory regulations;

- Improved production efficiency and possibly reduced production costs.

As nursery industry personnel in central and northern Florida contemplate the use of BMPs, the most difficult challenge will be establishing a consensus of the industry that BMPs are needed and not developing a consensus of conflict that becomes the content of new BMPs. BMPs can enhance production while achieving environmental stewardship, yet they are economical and feasible to implement.

\section{Conclusion}

Moscovici and Doise (1994) indicate that consensus is characterized by: 1 ) choices, 2 ) public apathy, 3 ) examination of knowledge, 4) communication /discussion, and 5) legitimacy by participation. In southern Florida, consensus of the nursery industry regarding solving a water quality issue exhibited these characteristics. The nursery industry had a choice to participate in solving the water quality issue with voluntary BMPs, or let mandated regulation prevail. There were skeptics or those with apathy for 
the process of collecting information to solve the issue, but most people were willing to examine and embrace the pertinent information, including the relevant research.

Communication and discussion were enhanced by a facilitator who conducted regular meetings with the team responsible for developing the content of each chapter in a BMP guide. The team approach for developing the content with participation by nonscientific or nonacademic persons, along with scientific or academic persons involved in the consensus building process, resulted in a feeling of ownership for the participants, and likely a greater participation or use of the BMPs when finalized. In addition, the state nursery organization apprised members of the latest information regarding the development of a BMP guide.

\section{Literature cited}

Adorisio, C., D. Meiers, P. Sievers, B. Powell, C. Miessau, and E. Marshall. 2004. Everglades Stormwater Program basins source control schedules and strategies. 28 Nov. 2005. <http://www. sfwmd.gov/org/reg/esp/pdfs/esp_annrpt_2004.pdf>.

Florida Statutes. 2000. The Everglades Forever Act. 28 Nov. 2005. <http:/ / www. sfwmd.gov/org/wrp/wrp_evg/projects/ efa/html>.

Moscovici, S. and W. Doise. 1994. Conflict and consensus. Sage Publ., Thousand Oaks, Calif.

Yeager, T. (ed.). 2005. Florida container nursery BMP guide. 29 Mar. 2006. <http://www.floridaagwaterpolicy.com/ PDFs/BMPs/nursery\%20bmp\%20manu al\%20entire.pdf>.

Yeager, T., T. Bilderback, D. Fare, C. Gilliam, A. Niemiera, and K. Tilt. 1997. Best management practices-Guide for producing container-grown plants. Southern Nursery Assn., Atlanta. 